\title{
Self-Regulation Students' Online Learning Behavior in General Education Courses of University of Phayao
}

\author{
https://doi.org/10.3991/ijet.v16i14.19897 \\ Narin Nonthamand ${ }^{(凶)}$ \\ University of Phayao, Phayao, Thailand \\ n. nonthamandegmail.com \\ Narissara Suaklay \\ University of Phayao, Phayao, Thailand
}

\begin{abstract}
The purposes of this research were (1) to survey the selfregulation behavior of University of Phayao students (2) to survey the online learning behavior of University of Phayao students, and (3) to study factors that influence online learning behavior in general education courses of University of Phayao students. The sample group consisted of 450 students who enrolled for online classes in general education course. The instrument of assessment was a questionnaire form on the self-regulation of an online course and online learning behavior. The data collected were analyzed using a set of standard statistics as follows: mean (M), standard deviation (S.D.), and Multiple Regression Analysis.

The results of the research were that (1) the students' self-regulation was mainly on decision-making ( $\mathrm{M}=3.89$; S.D. $=0.62)$, (2) the students' online learning behavior was mainly on the learner's aspect $(\mathrm{M}=3.88$; S.D. $=0.77)$, and (3) the factors that support students' online learning behavior consisted three factors which are self-observation, decision-making, and self-regulation.

The Multiple Regression Analysis indicated that self-reaction, selfobservation, and decision-making affected the factors supporting online learning behavior of the general education course of the University, which increased by 0.683 units. This indicated that the self-reaction factor was the most important factor that supports the online learning behavior of the students, followed by the self-observation and the decision-making, respectively.
\end{abstract}

Keywords - Self-Regulation, Online Learning Behavior, General Education Course

\section{Introduction}

Due to the rapid and continuous development of technology and communication, educational institutions and agencies have arranged online classes for those who are not registered in the curriculum. This allows them to have the option to study at their convenient place and time. Online learning consists of the following elements: (1) learner, (2) instructor, (3) learning activity, (4) participation, (5) media, (6) measurement, and assessment [1]. 
The teaching and learning of general education courses are provided through an online platform where each subject or course contains both synchronous learning and asynchronous learning, depending on the individual instructor's teaching preference [2]. Through online learning, if students cannot self-regulate, they will not be able to achieve learning outcomes in accordance with the procedures constructed by the instructor. This also covers self-learning on media contents, exchange of opinions, understanding the course content, and being unable to apply the knowledge to their daily lives. Most importantly, they will be unable to achieve the learning objectives of the course.

Self-regulation in online learning will motivate the learner to vision their target, enhancing the subject's comprehension, and having long-term memory. Students will be able to apply better knowledge than those who only learn from the instructor [3]. Self-regulation leads oneself to a particular advantage where learners see his/her value and life-long learning [4]. Students will be able to analyze their own need, dependently determine their goal, plan toward a destination, seek further knowledge [5], implement an action and responsibility for their studies, self-regulation and creating self-motivation [6], analyze their actions and conduct self-assessment, and eventually apply such information to improve themselves [7]. Considering the importance of self-regulation and online learning behavior, when an instructor is aware of selfregulation, behavior, or factors that influence an online class as guidance toward selfcontrol during the online course, it creates an emphasis on the self-regulation among learners.

The purposes of this research were to survey students' behavior in relation to their self-regulation and online learning behaviors. The following research objectives were used to guide this study:

1. To survey the self-regulation behavior of University of Phayao students.

2. To survey the online learning behavior of University of Phayao students

3. To study factors that influence online learning behavior in general education courses of University of Phayao students.

\section{Conceptual Framework}

In this study, the researcher followed the concepts on self-regulation and online learning. Variables of analysis were categorized as independent and dependent as follows:

1. Independent Variable (Predictor) - (1) Self-Observation, (2) Decision-Making, and (3) Self-Reaction

2. Dependent Variable (Criterion variable) - (1) Learner, (2) Instructor, (3) Learning Activities, (4) Interactive, (5) Technology, and (6) Measurement and Evaluation 


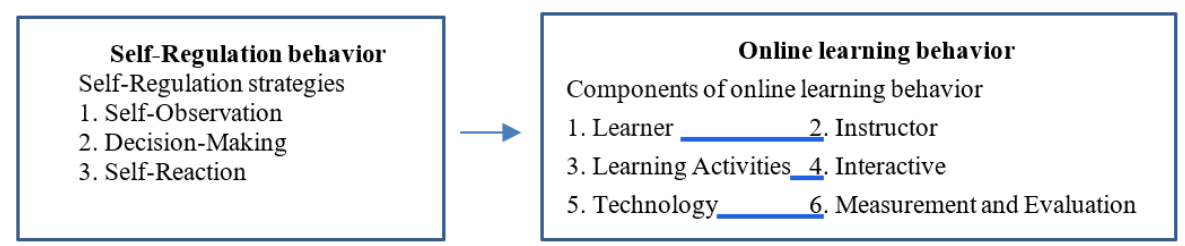

Fig. 1. Shows the Conceptual Framework of this study.

\section{$3 \quad$ Methodology}

Research on self-regulation that affects the online learning behavior of general education courses among students from the University of Phayao is a survey-based research.

\subsection{Population and sample group}

Population: 17,715 students with bachelor's degrees from the University of Phayao who enrolled in the general education courses in the 1st semester of 2020.

Samples: 450 students with bachelor's degrees from the University of Phayao who enrolled in the general education courses in the 1st semester of 2020. The samples were selected based on sampling procedure of Taro Yamane [8]. The original study conducted by Yamane [8] involved 382 students. In this study, a sample group of 450 students was selected to prevent data loss.

\subsection{Research tools}

A questionnaire was applied to assess self-regulation in online learning behavior. The development and quality validation procedures of the tools were as follows:

1. To study the concept, theory, and related researches and analyze variables on selfregulation in an online learning behavior.

2. To develop questionnaires with three sections as follows:

Section 1 General information includes gender, education year, and faculty

Section 2 Self-regulation behaviors containing 18 items assigned with a rating scale from 1-5, which were very high, high, medium, low, and very low.

Section 3 Opinions on online learning consisting of 26 items assigned with a rating scale of 1-5: very high, high, medium, low, and very low.

3. To evaluate language competency and test for content validity using the Index of Item-Objective Congruence (IOC) by Rovinelli and Hambleton [9]. Five experts involved in this examination consisted of three experts from the field of educational technology and two from the field of educational measurement and evaluation. The IOC was used to evaluate the questionnaire items based on a score 
range of -1 to +1 . According to the review on IOC, all items were within the range of $0.60-1.00$.

4. To compute the internal consistency reliability of the questionnaire of 100 students of the University of Phayao using Cronbach's alpha [10]; this method focuses on one measurement error. The common standard of Cronbach's alpha reliability estimate should be at least 0.70 [11]. The reliability test results showed that the Cronbach's alpha for the 18 items in Section 2 and Section 3 were 0.919 and 0.954, respectively. This shows that the entire questionnaire can be used to collect data for scientific purposes.

\subsection{Data analysis}

The collected data of the participants were analyzed using descriptive statistics. The Stepwise Multiple Regression Analysis method was applied in estimating the research model result for the 3th research objective.

\section{$4 \quad$ Results}

Part 1: The results of self-regulation of the students who enrolled in online classes are shown in Table 1.

Table 1. The mean and standard deviation of self-regulation level of University of Phayao students in overall $(n=450)$

\begin{tabular}{|l|c|c|c|}
\hline Self-Regulation strategies & M & S.D. & Self-Regulation level \\
\hline Decision-Making & 3.89 & 0.62 & High \\
\hline Self-Reaction & 3.80 & 0.57 & High \\
\hline Self-Observation & 3.79 & 0.59 & High \\
\hline Mean & 3.82 & 0.54 & High \\
\hline
\end{tabular}

The overall output demonstrated that decision-making affected self-regulation the most $(M=3.89$, S.D. $=0.62)$, followed by self-reaction $(M=3.80$, S.D. $=0.57)$, and selfobservation $(\mathrm{M}=3.79$, S.D. $=0.59)$, respectively. All behaviors were ranked as high.

Part 2: The results of online learning behavior of the students are shown in Table 2.

Table 2. The mean and standard deviation of online learning behavior level of University of Phayao students in overall $(\mathrm{n}=450)$

\begin{tabular}{|l|c|c|c|}
\hline \multicolumn{1}{|c|}{ Components } & M & S.D. & Online learning behavior level \\
\hline Learner & 3.88 & 0.77 & High \\
\hline Instructor & 3.81 & 0.71 & High \\
\hline Learning Activity & 3.66 & 0.67 & High \\
\hline Interactive & 3.88 & 0.83 & High \\
\hline Technology & 3.58 & 0.81 & High \\
\hline Measurement and Evaluation & 3.55 & 0.76 & High \\
\hline Mean & 3.67 & 0.64 & High \\
\hline
\end{tabular}


When considering the overall components, students' opinions toward online learning behavior focused on the learner component $(M=3.88$, S.D. $=0.77)$ and interactive component $(M=3.88$, S.D. $=0.83)$, followed by the instructor component $(M=3.81$, S.D. $=0.71)$ and learning activity component $(\mathrm{M}=3.66$, S.D. $=0.67)$, respectively. All behaviors were ranked as high. The results are evenly distributed along the regression line. This is the assumption made in linear correlation.

The data analysis from descriptive statistics in part 1-2 was normally distributed based on the mean and standard deviation of the sample according to the assumptions of multiple regression analysis.

Part 3: The results of the factors of self-regulation that influenced online learning behavior of the students are shown in Table 3.

Table 3. The results of correlation between the variables

\begin{tabular}{|l|c|c|c|c|}
\hline \multicolumn{1}{|c|}{ Variables } & X1 & X2 & X3 & Y \\
\hline Self-Observation (X1) & 1.00 & & & \\
\hline Decision-Making (X2) & $0.74^{* *}$ & 1.00 & & \\
\hline Self-Reaction (X3) & $0.74^{* *}$ & $0.78^{* *}$ & 1.00 & \\
\hline Online Learning Behavior (Y) & $0.55^{* *}$ & $0.56^{* *}$ & $0.61^{* *}$ & 1.00 \\
\hline
\end{tabular}

** Correlation significant at the level 0.01 (two-tailed)

When considering the correlation between the three factors of self-regulation (independent variables), which included self-observation, decision-making and selfreaction and online learning behavior of the students (dependent variables), the three factors significantly correlated with online learning behavior at .01, and all showed positive correlation ranged between 0.55 to 0.78 .

When considering the correlation between the three factors of self-regulation (independent variables), it was found that the 23 items significantly correlated statistically at .01 and all were positive correlation, and such correlation should not exceed 0.80 [12]. This is the correlation and regression equivalent of the homogeneity of variance assumption.

After testing the correlation between variables for multiple regression analysis, it was found that independent variables showed significant positive correlation at .01 , and all independent variables showed multicollinearity below 0.80. Accordingly, all independent variables (the three factors of self-regulation), which consisted of selfobservation, decision-making, and self-reaction, were applied in the Stepwise Multiple Regression Analysis as shown in Table 4.

Table 4. The results of predicting equation with Stepwise Multiple Regression Analysis

\begin{tabular}{|c|c|c|c|c|c|}
\hline Model & R & R Sqaure & Adjusted R Square & F & Sig. \\
\hline 1 & 0.610 & 0.372 & 0.372 & $2122.016^{*}$ & .000 \\
\hline 2 & 0.627 & 0.393 & 0.393 & $1159.840^{*}$ & .000 \\
\hline 3 & 0.632 & 0.399 & 0.399 & $793.596^{*}$ & .000 \\
\hline
\end{tabular}

* Model significant at the level 0.05 (two-tailed)

After applying each independent variable to Stepwise Multiple Regression Analysis, a method of regression multiple variables while simultaneously removing those that are not important by adding variables and taking others away at the same time. 
An alternative approach to the direct method was chosen because the most predictive regression is where few variables explain the variability in the dependent variable. Moreover, excluding additional variables that have negligible contribution to our prediction. Therefore, we selected a model that forecasted the highest value. It was shown that model 3, which consisted of the three factors of self-regulation had multiple correlations with the student's online learning behavior, significantly at .05 . With the prediction coefficient $\left(\mathrm{R}^{2}\right)=0.399$, this indicates that nearly half of the variability in online learning behavior $(\mathrm{Y})$ can be explained by changes in Self-Reaction $\left(\mathrm{X}_{3}\right)$, Self-Observation $\left(\mathrm{X}_{1}\right)$ Decision-Making $\left(\mathrm{X}_{2}\right)$ as shown in Table 5. Therefore, in this case, despite the statistical significance, we have every right to question the value of $\mathrm{X}$ as a predictor of $\mathrm{Y}$, that showed the self-regulation factor supporting online learning behavior at 39.90 percentage. Three factors cooperated to support online learning behavior in the general education course of the University of Phayao students.

Table 5. Indicated the correlation coefficient Stepwise Multiple Regression Analysis in predicted the factors supporting online learning behavior of the University of Phayao students $(n=450)$

\begin{tabular}{|l|c|c|c|c|c|}
\hline \multicolumn{1}{|c|}{ Predictor } & b & S.E. & $\boldsymbol{\beta}$ & $\mathbf{t}$ & Sig. \\
\hline Self-Reaction $\left(\mathbf{X}_{\mathbf{3}}\right)$ & 0.423 & 0.025 & 0.377 & 16.734 & 0.000 \\
\hline Self-Observation $\left(\mathbf{X}_{\mathbf{1}}\right)$ & 0.183 & 0.023 & 0.169 & 8.092 & 0.000 \\
\hline Decision-Making $\left(\mathbf{X}_{2}\right)$ & 0.141 & 0.023 & 0.137 & 6.123 & 0.000 \\
\hline
\end{tabular}

$\mathrm{a}=0.822, \mathrm{R}=0.632, \mathrm{R} 2=0.399, \mathrm{~F}=793.596^{*}$, sig. $=.000$

It was found that the three factors of self-regulation that had an effect on the students' online learning behavior, ordered by the scale of the influence, which included self-reaction, self-observation, and decision-making, had multiple correlations with the online learning behavior at 0.632 , the prediction coefficient $(\mathrm{R} 2)=.399$ with the self-regulation factor supporting online learning behavior at 39.90 percentage. Three factors cooperated to support online learning behavior of the students. The equation used to estimate the raw score is:

online learning behavior $=0.822+0.423$ (self-reaction) +0.183 (self-observation) +0.141 (decision-making)

The equation of Multiple Regression Analysis is used to determine self-reaction (X3), self-observation (X1) and decision-making (X2) in the factors supporting online learning behavior.

The Prediction equation for factors supporting online learning behavior has a standard score as follows:

$$
\mathrm{Z}_{\text {online learning behavior }}=0.377 \mathrm{Z}_{\text {self-reaction }}+0.169 \mathrm{Z}_{\text {self-observation }}+0.137 \mathrm{Z}_{\text {decision-making }}
$$

From the Multiple Regression equation to indicate the self-reaction (X3), the self-observation (X1) and the decision-making (X2) affected the factors supporting online learning behavior of the students increased by 0.683 unit. This demonstrates that the self-reaction factor was the most important factor that affects the student's online learning behavior, followed by self-observation and decision-making, respectively. 


\section{Discussion}

\section{Self-regulation in online learning behavior}

In the overall conclusion of self-regulation demonstrated that decision-making affected self-regulation the most, followed by self-reaction and self-observation, respectively. All behaviors were at a high level. According to the results, decisionmaking is a logical thinking toward any daily routine activities, which will eventually result in positive and negative behaviors. This applied to the students who need to decide their learning, whether in an actual class or online class [13]. According to the finding of Jongjaisurathum et al. (2015) [14] self-regulation in learning in the 21st century showed that self-regulation in learning affects the study results. Therefore, instructor must encourage learner to improve and develop themselves continually. The importance of instructors should also be addressed since it is a surrounding factor that directly affects learner [15].

2. Online learning behavior of the students who enrolled in the general education courses

Overall, the results demonstrated that the highest behaviors were learner component and interactive component, followed by was instructor component and learning activity component, respectively. All behaviors were ranked as high. Accordingly, learner should be equipped with technological tools such as devices, learning apparatuses, and internet networks, including skills and abilities to utilize such tools in learning. Having experience in using online learning tools as well as technology will enhance learners in classroom. This is consistent with the concept which states that online learning is a taught based on computer and mobile devices, internet and cloud computing, and available learning management system [16]. In addition, contents from teachers can be transferred through learning materials [17]. The learner can participate in online educational activities beyond the limitations of time and place (anywhere-anytime learning) [18].

3. Factors of self-regulation that influenced online learning behavior

The three factors of self-regulation affected the student's behavior in online learning. The factor that affected the student's behavior the most was self-reaction, followed by self-observation and decision-making, respectively.

Self-reaction affected the students' online learning behavior because the students should evaluate themselves based on their decision to study. This includes the student's ability to study according to their needs, knowledge of their learning style, their enjoyment in learning activities, self-assessment, and to apply their skills to real life work.

Self-observation followed self-reaction since it is a reception that relates to their thoughts, feelings, and actions toward learning. Self-observation will allow the students to acknowledge learning topics with their skills and interest given that the student will be able to manage learning time themselves. This conforms to the concept 
where self-observation is a procedure to comprehend a person's awareness and selfcontrol [19].

Finally, in terms of decision-making, logical thinking toward the learning will help the students study according to their needs, discover relevant aptitudes and interests, manage their learning times effectively, improve their learning activity engagement, and search for additional knowledge from various resources.

Since it was crucial that the students possess the three factors in online learning; therefore, online teaching or supporting system should be programed to encourage learners to develop their self-regulation in every activity. For instance, providing students with the options to study the content in various formats such as video, animations, motion graphics, online publications and engage in group topic discussions. Additionally, students can be assigned with online classes for a fixed duration in consistent with the concept [20] of self-regulation procedures. Such procedures include three steps as follows: (1) self-observation: marked as a success of self-regulation partially as a result of consistent and precise observation and record of oneself, (2) Judgment Process: data derived from self-observation, without judgment process, has slight effect on the change of human's behavior, and (3) Self-reaction: development of assessment and skills of decision-making will lead to self-reaction.

\section{Suggestion}

Our suggestions for applying the research results are as follows:

1. The research results can apply to develop students' behavior in an online class. The instructor should design an activity that encourages self-regulation, covering three factors among students or encourage students to self-investigate through various teaching activities. Such encouragement will create reception toward thoughts, feeling, and actions. Eventually, students will be able to think logically to make a decision based on their needs and are able to evaluate their behavior as a result of deciding self-regulation through online learning.

2. According to the research result, the variables that estimate online learning best is self-reaction. Thus, the university may apply this concept as a guide to arrange online courses to enhance the ability of self-regulation and self-reaction among students. Furthermore, initiate activities designed to motivate students to enjoy seeking the class's answers, exchanging opinions, and starting actual practice to enable them to link the learning content to their long-term target. Eventually, the student will be able to conduct self-assessment and discover their needs, skills, and abilities to support their planning and decisions toward learning and their future careers. 
Our suggestions for future research are as follows:

1. We suggest conducting a study on qualitative and quantitative data to get in-depth data of the students to use as a guide for online teaching and learning to meet the student's needs.

2. We also suggest conducting a comparative study between faculties where the result will be applied as a guide for an online teaching and learning integral to the student's nature, aspects, and learning format within individual faculty.

\section{$7 \quad$ Acknowledgement}

Supportive scholarship granted by "New Graduates General Education towards Quality" in 2020, University of Phayao.

\section{References}

[1] Ally, M. (2004). Foundations of educational theory for online learning. Theory and practice of online learning, 2, 15-44.

[2] Watts, L. (2016). Synchronous and asynchronous communication in distance learning: A review of the literature. Quarterly Review of Distance Education, 17(1), 23.

[3] Knowles, M. S. (1975). Self-directed learning: A guide for learners and teachers.

[4] Kicken, W., Brand - Gruwel, S., \& van Merriënboer, J. J. (2008). Scaffolding advice on task selection: a safe path toward self - directed learning in on - demand education. Journal of Vocational Education and Training, 60(3), 223-239. https://doi.org/10.1080/ 13636820802305561

[5] Boekaerts, M., Zeidner, M., \& Pintrich, P. R. (Eds.). (1999). Handbook of self-regulation. Elsevier.

[6] Majumdar, B., Roberts, J., Knechtel, R., Noesgaard, C., Campbell, K., \& Tkachuk, S. (1998). Comparison of self and faculty directed learning of psychomotor skills. Advances in health sciences education, 3(1), 15.

[7] Duckworth, A. L., Grant, H., Loew, B., Oettingen, G., \& Gollwitzer, P. M. (2011). Self regulation strategies improve self - discipline in adolescents: Benefits of mental contrasting and implementation intentions. Educational Psychology, 31(1), 17-26. https://doi.org/10.1080/01443410.2010.506003

[8] Yamane, Taro. (1967). Statistics: An Introductory Analysis, 2nd Edition, New York: Harper and Row.

[9] Rovinelli, R. J., \& Hambleton, R. K. (1977). On the use of content specialists in the assessment of criterion-referenced test item validity. Dutch Journal of Educational Research, 2, 49-60.

[10] Cronbach, L. J., \& Meehl, P. E. (1955). Construct validity in psychological tests. Psychological bulletin, 52(4), 281.

[11] Shultz, K. S., Whitney, D. J., \& Zickar, M. J. (2020). Measurement theory in action: Case studies and exercises: Routledge. https://doi.org/10.4324/9781003127536

[12] Brian S. Everitt. (2010). Mulitivariable Modeling And. Mulitivariate Analysis Eor The Behavioral Sciences. Taylor \& Francis Group, LLC. 
[13] Bandura, A. (1986). The explanatory and predictive scope of self-efficacy theory. Journal of social and clinical psychology, 4(3), 359-373.

[14] Salinee Jongjaisurathum, Numchai Supparerkchaisakul, \& Winai Damsuwan. (2015). SelfRegulated Learning strategies of 21th century. Journal of Behav ioral Science for Development, 7(1), 15-26.

[15] Zarouk, M., Olivera, E., Peres, P., \& Khaldi, M. (2020). The Impact of Flipped Project Based Learning on Self-Regulation in Higher Education. International Journal of Emerging Technologies in Learning (iJET), 15(17), 127-147. https://doi.org/10.3991/ijet. $\underline{\mathrm{v} 15 \mathrm{i} 17.14135}$

[16] Clark, R. C., \& Mayer, R. E. (2003). E-learning and the science of instruction: Proven guidelines for consumers and designers of multimedia learning. New York: John Wiley \& Sons. https://doi.org/10.1002/9781118255971

[17] Jin, D., \& Li, Y. (2020). A Teaching Model for College Learners of Japanese Based on Online Learning. International Journal of Emerging Technologies in Learning (iJET), 15(15), 162-175.https://doi.org/10.3991/ijet.v15i15.15929

[18] Norah A., \& Shabir K. (2020). Students Satisfaction with Online Learning Experiences during the COVID-19 Pandemic. International Journal of Emerging Technologies in Learning (iJET), 15(21), 246-267. https://doi.org/10.3991/ijet.v15i21.15647

[19] Schunk D.H., \& Zimmerman B.J. (1988). Self-regulated learning: From teaching to selfreflective practice. New York, NY: Guilford Press.

[20] Bandura, A. (2010). Self-efficacy the corsini encyclopedia of psychology. John Wiley \& Sons, Inc. doi, 10(9780470479216), 1-3.

\section{Authors}

Narin Nonthamand is a lecturer at the Department of Educational Technology, School of education, University of Phayao, Thailand (narin.no@up.ac.th)

Narissara Suaklay is a lecturer at the Department of Educational Measurement and Evaluation, School of education, University of Phayao, Thailand (narissara.su@ up.ac.th)

Article submitted 2020-11-18. Resubmitted 2021-04-21. Final acceptance 2021-04-22. Final version published as submitted by the authors. 